\title{
An atypical case of Kawasaki disease presenting with cholestatic jaundice
}

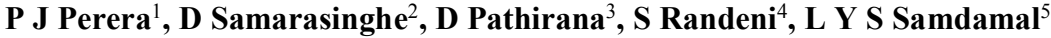

Sri Lanka Journal of Child Health, 2015; 44(1): 58-60

(Key words: (Kawasaki disease; atypical; cholestatic jaundice)

\section{Introduction}

Kawasaki disease (KD) is dreaded because of its potential to cause coronary aneurysms. Cholestatic jaundice is a less known presentation of $\mathrm{KD}$ and no previous cases are reported from Sri Lanka. Here we present a ten year old boy with KD, presenting initially with cholestatic jaundice.

\section{Case report}

A previously healthy 11 year old boy was admitted with high fever, myalgia and tea coloured urine of 3 days duration. He did not have anorexia, nausea or vomiting. He had deep icterus and bilateral tender cervical lymphadenopathy. He had no skin rashes, conjunctivitis or changes in oral cavity and extremities. He had tender hepatomegaly, liver being felt $4 \mathrm{~cm}$ below the right costal margin. Gallbladder and spleen were not palpable.

On admission, his total serum bilirubin was $66.9 \mu \mathrm{mol} / \mathrm{L}$ with a direct fraction of $52.1 \mu \mathrm{mol} / \mathrm{L}$. White blood count was $15.2 \times 10^{9} / \mathrm{L}$, with $81 \%$ neutrophils. Platelet count was $250 \times 10^{9} / \mathrm{L}$ initially, but rose to $725 \times 10^{9} / \mathrm{L}$ during the second week. C-reactive protein was 96, erythrocyte sedimentation rate 120 in first hour, urine bile salts positive and urinary urobilinogen $3+$. Serology for Hepatitis A \& C, Leptospira and Mycoplasma was negative. Hepatitis B surface antigen, Monospot test and antinuclear antibodies were negative.

On third day after admission, he developed bilateral, non-purulent conjunctivitis and ultrasound scan of abdomen revealed hydrops of the gallbladder. At this stage KD with an atypical presentation was considered in the differential diagnosis. Echocardiogram, done on the seventh day of illness, revealed an $8.1 \mathrm{~mm}$ giant aneurysm

${ }^{1}$ Senior Lecturer in Paediatrics, Faculty of Medicine, University of Kelaniya, ${ }^{2}$ Consultant Paediatric Cardiologist, Lady Ridgeway Hospital, Colombo, ${ }^{3}$ Consultant Paediatrician, Nawaloka Hospital, Colombo, ${ }^{4}$ Senior Registrar in Paediatrics, ${ }^{5}$ Registrar in Paediatrics, University Paediatric Unit, Teaching Hospital, Ragama,

(Received on 22 November 2011: Accepted after revision on 20 December 2013) in the left anterior descending artery (LAD) and a 6 $\mathrm{mm}$ sized aneurysm in the right coronary artery. Both were proximal and fusiform. Within 2 hours of starting patient on intravenous immunoglobulin (IVIG) $2 \mathrm{~g} / \mathrm{kg}$ he had anaphylactic shock. Anaphylaxis was managed with hydrocortisone and adrenalin and IVIG was continued at a slower rate over the next 24 hours, without further reactions. The temperature settled immediately with IVIG. Echocardiogram was repeated on the $12^{\text {th }}$ day and the aneurysms were $9.5 \mathrm{~mm}$ in LAD and $5 \mathrm{~mm}$ in the right coronary artery.

During the course of the illness inflamed oral mucosa, skin rashes or desquamation of skin were not noted in this patient. Other than for coronary aneurysms the child made an uneventful recovery and jaundice settled within first week of admission. Child was started on anti-inflammatory dose of aspirin and warfarin. He was discharged from the hospital after 14 days of hospital stay.

\section{Discussion}

Atypical KD is a dilemma to the clinician. Atypical / incomplete presentation is observed in about $20 \%$ of the $\mathrm{KD}$ patients ${ }^{1}$. Coronary artery involvement is around $15-25 \%$ in untreated KD but IVIG administration within the first 10 days reduces the risk to about $2-4 \% \%^{2,3,4}$. However, because of the cost and side effects one should be selective when administering IVIG. Serious side effects like anaphylaxis and acute renal failure are reported following IVIG $^{5}$ but delaying IVIG increase the risk of coronary complications in $\mathrm{KD}^{6,7}$.

$\mathrm{KD}$ is associated with vasculitis in small and medium sized arteries, predominantly in young children $^{8}$. Only about $7.5 \% \mathrm{KD}$ patients are more than 9 years old but they carry a higher risk of coronary abnormalities ${ }^{9}$. Typical diagnostic criteria of $\mathrm{KD}$ include at least five days of fever plus four features out of the following: bilateral non-purulent conjunctival injection, oral mucosal changes, extremity changes, rash and unilateral cervical lymphadenopathy $>1.5 \mathrm{~cm}^{10,11}$. Thrombocytosis, hydrops of the gallbladder and desquamation of periungual skin are also characteristic of $\mathrm{KD}^{12}$.

Apart from high fever, our patient did not have any diagnostic features of KD initially. This case 
highlights the importance of considering $\mathrm{KD}$ in any child presenting with high fever of unknown aetiology, even though classical features are absent. Though rare, KD presenting as cholestatic jaundice is well documented ${ }^{13,14,1}$. However, coronary aneurysms and cholestatic jaundice in the same patient has been reported only once before ${ }^{12}$. Although KD mostly affects small children, as in our patient, cholestasis is observed mainly in older children, with an average age of 5.2 years.

Exact explanation for cholestasis in $\mathrm{KD}$ is not known. In KD with cholestasis, the gallbladder is oedematous and acalculous. Enlarged mesenteric lymph nodes are reported ${ }^{16}$. Various mechanisms have been proposed to explain cholestasis in $\mathrm{KD}$. Obstruction due to vasculitis or enlarged lymph nodes at porta hepatis, cystic duct wall oedema, inflammation of liver and gallbladder serosa or intrahepatic cholangitis ${ }^{16,17}$ are among them.

In $\mathrm{KD}$, coronary aneurysms can be seen as early as 4 days, but peak incidence is around 4 weeks $^{18}$. In our patient giant coronary aneurysms were present by the seventh day of illness. Coronary aneurysms are termed giant, when internal diameter is $>8$ $\mathrm{mm}^{19}$. Approximately $50 \%$ of aneurysms regress within 5 years and the majority of small coronary aneurysms regress within 2 years ${ }^{20}$. Regression of coronary aneurysms depends on initial size $(<5 \mathrm{~mm}$ more likely than $>8 \mathrm{~mm}$ ), age of patient (more likely when age $<1$ year), morphology (fusiform aneurysms more than saccular aneurysms), and distal aneurysms more than proximal ${ }^{21}$.

Even when aneurysms are already present, IVIG should be administered because IVIG is expected to enhance resolution of aneurysms. In our patient IVIG had to be stopped due to anaphylactic shock, but with slower infusion rate over 24 hours complete dose was administrated without further reactions. This approach is useful in patients developing reactions with IVIG.

Thrombus formation within coronary aneurysms leading to myocardial infarction is a major concern. Therefore the patient was started on aspirin, and warfarin was given to keep the international normalized ratio (INR) between 2 and 2.5. The patient will be followed up with repeated echocardiograms to assess the progress. Stress test and angiography will be considered if clinical features suggest stenosis of coronary arteries ${ }^{22}$.

In a child with unexplained fever and cholestatic jaundice, atypical KD should be considered. This presentation is more likely among older children with KD. In children who develop anaphylactic reactions with IVIG, slow infusion over 24 hours could reduce the risk of reactions.

\section{References}

1. Falcini F, Cimaz R, Calabri GB, et al. Kawasaki disease in northern Italy: a multicenter retrospective study of 250 patients. Clinical and Experimental Rheumatology 2002; 20:421-6.

2. Muta H, Ishii M, Egami K, et al. Early intravenous gamma-globulin treatment for Kawasaki disease: the nationwide surveys in Japan. Journal of Pediatrics 2004; 144:496-9. http://dx.doi.org/10.1016/j.jpeds.2003.12.033

3. Son MB, Gauvreau K, Ma L, et al. Treatment of Kawasaki disease: analysis of 27 US paediatric hospitals from 2001 to 2006 . Pediatrics 2009; 124:1-8. http://dx.doi.org/10.1542/peds.2008-0730

4. Newburger JW, Takahashi M, Gerber MA, et al. Diagnosis, treatment, and long-term management of Kawasaki disease: a statement for health professionals from the Committee on Rheumatic Fever, Endocarditis, and Kawasaki Disease, Council on Cardiovascular Disease in the Young, American Heart Association. Pediatrics 2004; 114:1708-33. http://dx.doi.org/10.1542/peds.2004-2182

5. Pasatiempo AM, Kroser JA, Rudnick M, Hoffman BI. Acute renal failure after intravenous immunoglobulin therapy. Journal of Rheumatology 1994; 21(2):347-9.

6. Burns JC, Wiggins JW Jr, Toews WH, Newburger JW, Leung DY, Wilson H, et al. Clinical spectrum of Kawasaki disease in infants younger than 6 months of age. Journal of Pediatrics 1986; 109(5):759-63. http://dx.doi.org/10.1016/S00223476(86)8068 9-8

7. Rowley AH, Gonzalez-Crussi F, Gidding SS, Duffy CE, Shulman ST. Incomplete Kawasaki disease with coronary artery involvement Journal of Pediatrics 1987; 110(3):409-13. http://dx.doi.org/10.1016/S00223476(87)8050 $\underline{3-6}$

8. Jin Yu J. Diagnosis of incomplete Kawasaki disease. Korean Journal of Pediatrics 2012; 55(3): 83-7. http://dx.doi.org/10.3345/kjp.2012.55.3.83 
9. Momenah T, Sanatani S, Potts J, et al. Kawasaki Disease in the older child. Pediatrics 1998; 102; 7 .

http://dx.doi.org/10.1542/peds.102.1.e7

10. Diagnostic guidelines for Kawasaki disease. Council on Cardiovascular Disease in the Young, Committee on Rheumatic Fever, Endocarditis, and Kawasaki Disease, American Heart Association. Circulation 2001; 103(2): 335-6.

11. Japan Kawasaki Disease Research Center, Japan Kawasaki Disease Research Committee; c2012. Diagnostic guidelines of Kawasaki disease. Available from:

http://kawasaki-disease.org/diagnostic

12. Singh R, Ward C, Walton M, et al. Atypical Kawasaki disease and gastrointestinal manifestations. Paediatric Child Health 2007; 12:235-7.

13. Mercedes Ibáñez-Alcalde,Miguel SánchezForte, Francisco Giménez-SánchezÁngeles Ortega-Montes, Gema Martínez-Espinosa. Cholestasis as the initial feature of Kawasaki disease. The Pediatric Infectious Disease Journal 2012; 31:766-7. http://dx.doi.org/10.1097/INF.0b013e318253a $\underline{1 \mathrm{~d} 8}$

14. Taddio A, Pellegrin MC, Centenari C, Filippeschi IP, Ventura A, Maggiore G. Acute febrile cholestatic jaundice in children: Keep in mind Kawasaki disease. Journal of Pediatric Gastroenterology and Nutrition 2012; 55(4): 380-3.

http://dx.doi.org/10.1097/MPG.0b013e318255 $\underline{13 \mathrm{de}}$

15. Falcini F, Resti M, Azzari C, Simonini G, Veltroni M, Lionetti P Acute febrile cholestasis as an inaugural manifestation of Kawasaki's disease. Clinical and Experimental Rheumatology 2000; 18: 779-80.
16. Granel B, Serratrice J, Ene N, et al. Painful jaundice revealing Kawasaki disease in a young man. Journal of Gastroenterology and Hepatology 2004; 19:713-5. http://dx.doi.org/10.1111/j.14401746.2002.029 $\underline{03 . x}$

17. Valentini P, Ausili E, Schiavino A, et al. Acute cholestasis: atypical onset of Kawasaki disease. Digestive and Liver Disease 2008; 40:582-4.

http://dx.doi.org/10.1016/j.dld.2007.10.010

18. Kato H, Sugimura T, Akagi T. Long form consequences of Kawasaki disease: A 10 to 21 year follow-up of 594 patients. Circulation 1996; 94:1379-85 http://dx.doi.org/10.1161/01.CIR.94.6.1379

19. Brogan PA, Bose A, Burgner D, Shingadia D, Tulloh R, Michie C, et al. Kawasaki disease: An evidence based approach to diagnosis, treatment and proposals for future research. Archives of Disease in Childhood 2002; 86: 286-90. http://dx.doi.org/10.1136/adc.86.4.286

20. Shulman ST, Inocencio J, Hirsch R. Kawasaki disease. Pediatric Clinics of North America 1995; 42:1205-22.

21. Takahashi M, Mason W, Lewis AB. Regression of coronary aneurysms in patients with Kawasaki syndrome. Circulation 1987; 75:387-94. http://dx.doi.org/10.1161/01.CIR.75.2.387

22. Newburger JW. Kawasaki disease: Current treatment options. Cardiovascular Medicine 2000; 2:227-36. http://dx.doi.org/10.1161/01.CIR.75.2.387 